\title{
Editorial
}

\section{Tonia Gray}

Since writing my last editorial piece, two significant events have come and gone: the Olympics in Sydney; and the National Outdoor Education Conference held in Bendigo, Victoria. Unquestionably, both occasions showcased and celebrated "what we do well". Perhaps 1 am the eternal optimist who looks at the world through rose coloured glasses, but I firmly believe we have cause to celebrate Australian Outdoor Education. We do it damn well! Testimony to this claim is the quality of our own "home-grown" protégé. For instance, one of our rising stars, James Neill, has recently been appointed to a lecturing position at the prestigious University of New Hampshire's Outdoor Education programune. Now 1 could have it all wrong, but I get the impression that the USA is head-hunting our talent. In recent years we have lost Ray Handley and James Neill to the northern hemisphere and this begs the question "will we be impoverished by their departure?" Only time will tell. Undeniably, however, we are indebted to both James and Ray for their academic prowess and the advancement of Australian research and scholarship to unparalleled heights.

You will probably gather that I have mixed feelings as I type these words - on one hand I am delighted that two of our "top-guns" are heading overseas to further their career - but on the other, I wonder who will fill the void? On a positive note, I wanted to celebrate these achievements by inviting James to do the "Viewpoint" section in this edition. His parting words of wisdom are a timely rallying call and I hope we are inspired to greater heights as a result of his musings. And I am sure I speak on the industry's behalf by wishing James, Jackie and baby Thomas all the very best for their sojourn overseas. We will certainly miss you!

Turning my attention to the refereed section of this edition of AJOE, the first two papers examine differential gender outcomes in Outdoor Education - in particular, the sport of rock climbing. The first author, Jackie Kiewa posits that women are more likely to focus on "the inner journey" and on relationships, whilst men are more likely to focus on the activity and the process of striving to succeed" (pg 5). For those of us involved in facilitating mixed gender expeditions, a poignant message is offered by Kiewa -- "women in this study reported on a number of difficulties that interfered with their enjoyment of climbing with men. Men are more inclined to be patronising and somewhat impatient; their approach to climbing is competitive and (from the women's point of view) frantic; and they send mixed messages to their female climbing partners to be both dependent and capable" (pg 8). Quite clearly, contradictory pressures can be encountered when participating in mixed gender activities. Moreover, Kiewa suggests that "both men and women will benefit from programmes designed to support skills associated with the opposite gender. In this situation, women will benefit from programmes that encourage them to develop enthusiasm for and commitment to an activity, whilst men will benefit from programmes that encourage commitment to a partner within an activity" (pg 12). Undeniably, this paper has far reaching ramifications for programme designers.

Lou Preston's gender analysis takes a tangential theme. Adopting a "reflexive practitioner" approach, she unravels some intriguing dialogue which surfaced during the rock climbing debrief. Most notably, "one of the male participants suggested that he was disappointed that the male instructor hadn't shown them how to climb the climb much earlier in the day. He felt, and others agreed, that they had wasted a lot of time (and strength) trying to work out the appropriate moves and that if the instructor had demonstrated, from the outset, the techniques involved then more students would have been 'successful"' (pg 14). After a mature discussion of the salient issues, Preston concludes that she needs to "recognise the many voices within competing discourses and, perhaps more importantly, begin listening to these voices" (pg 16). The article is definitely a thought provoking read.
For many years (and in different forums), Outdoor Educators have long argued that our disassociation with nature is having a deleterious impact on our well-being. Brian Wattchow in his article picks up on this theme and takes it to further magnitude when he states that "the stated educational goals of many Outdoor Education programs are made vulnerable due to the 'hidden work' of technologies encountered and inattention to the significance of technology in experience" (pg 19). As a natural progression he purports that "human and environmental well being cannot be separated in the 'technological lifeworld' that humans are destined to inhabit and that Outdoor Education must sustain a broad range of technologically mediated experiences of the environment through, with and in the body" (pg 19). I found this paper resonated with my personal philosophy on Outdoor Education, especially in terms of our nature-estranged lifestyle and an over-reliance on technology as we head into the $21^{\text {st }}$ Century.

Deirdre Slattery's paper cogently argues that "a place has the actual or Jatent capacity to have a powerful impact on group, or some of its members.....so as professionals using a finite resource, we have a lot to gain from being well informed and skilful in presenting the land and its story" (pg 28). Speaking from personal experience after working with undergraduate students, Slattery suggests that "their capacity to observe, to understand and to explore is enhanced by knowledge and appreciation of the history of the landscape" (pg 30). Arguably, this paper is a refreshing read following the National Outdoor Education's Conference theme.

After Andy Martin's paper, I have come to the conclusion that we have a lot to learn from the Czechs with regard to how to use the outdoors and related experiential training. Their methods "offer such an holistic approach, by integrating a range of social, physical, creative, and emotional/reflection activities" (pg 34). In particular, I was drawn to the paper for two reasons. Firstly, "play" and "dance" is an integral component of the course. And secondly, it appears to be a "soulful" approach to Outdoor Education. This paper is a "must read" for anyone interested in "alternative" or "innovative" programme delivery.

Alison Lugg and Peter Martin's research has sought to describe the current state of play for Outdoor Education in Victorian schools. Sadly, the findings "paint a picture of Outdoor Education in schools as personal development education, conducted beyond school hours, by staff who are largely lacking in qualifications" (pg 42). Some key barriers and practical issues are discussed within the fabric of the paper and the information obtained from the study "can be used to further develop Outdoor Education in schools and as a profession" (pg 48).

The final paper in the refereed section by Pickett and Polley analyses "the implementation of Outdoor Education in South Australian schools and investigates the influences on this curriculum area" (pg 49). This paper has application for future government policy making and the implementation of Outdoor Education in the school curriculum.

Lastly, the National Outdoor Education Conference saw a "rearranging of the deck chairs" within the $A O E C$ and $A J O E$ ranks. Glyn Thomas has written a summary (see page 59) which honours and acknowledges the tireless work of Peter Martin in his role as AOEC chair - and welcomes Jackie Kiewa into the new position. So, let's join together, celebrate what we do well - and work towards profound simplicity. I'll leave you with the following thought:

Cherish your oision and your dreams as they are the children of your soul; the blue prints of your ultimate achieventents.

$$
\text { - Napoleon Hill }
$$

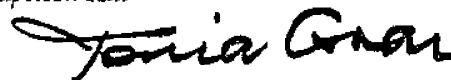

